\title{
Angled Abutment Transfer Jig: A Technical Report
}

\author{
Ahmad Y Imam ${ }^{1}$, Raghad A Al-Dabbagh ${ }^{2}$
}

\begin{abstract}
Aim: To introduce an angled abutment transfer jig that splints abutments securely together to facilitate easy and quick orientation.

Background: Transferring angled abutments from cast to patients' mouth could be tasking and time-consuming. Transfer jigs are often used to facilitate orientation of abutments into implant fixtures. However, with the available jigs, abutments could move out of place and thus pose a hassle in repositioning.

Technique: This technical report introduces an angled abutment transfer jig that consists of two impression copings screwed onto angled abutments which are splinted together with red acrylic resin. Access to abutment screws is feasible through slots created in the impression copings. Conclusion: The introduced jig is rigid and thus ensures very accurate and easy transfer of abutments into implants followed by accurate prosthesis seating.

Clinical significance: This transfer jig design allows clinicians to transfer the orientation of angled abutments from cast to patients' mouth with optimal speed and precision.

Keywords: Angled abutment, Implant, Technical report, Transfer jig.

The Journal of Contemporary Dental Practice (2020): 10.5005/jp-journals-10024-2821
\end{abstract}

\section{BACKGROUND}

The use of prefabricated angled abutments is becoming increasingly popular because it enables dentists to correct the position of implants with angled trajectories in quick and costeffective ways. Although there is evidence that angled abutments increase stress concentrations on prosthesis and around bone, yet the survival rate of implant-supported prosthesis is not significantly affected. ${ }^{1-4}$ However, using such abutments in the fabrication of implant-supported fixed partial dentures (FPD) can be time-consuming. This is because angled abutments, similar to custom-made abutments, can be positioned on implant fixtures at several orientations. ${ }^{5,6}$ Furthermore, as the number of angled abutments to be used increases, the number of possible orientations increases, making this clinical step very time-consuming. ${ }^{4}$

Accordingly, to accurately transfer the spatial relationship of angled abutments to each other and to implant fixtures from cast to mouth, transfer jigs are usually used..$^{5-9}$ The most common transfer jigs are fabricated from acrylic resin. ${ }^{7-9}$ They are commonly made solely of acrylic resin and have slots that guide abutment positioning. ${ }^{7-9}$ Abutments are usually, not securely attached to these jigs and could sometimes be tasking to orient them correctly into position intraorally. ${ }^{7-9}$ However, Wang et al. developed a transfer jig fabricated from splinted-temporary cylinders screwed onto angled abutments. This jig is rigid and facilitates easy and accurate transfer of abutment positions. ${ }^{5}$ Yet, the employed temporary cylinders will be unusable for further implant prosthetic work.

Due to the aforementioned limitations, the aim and objective is to develop an angled abutment transfer jig (Imam jig) to easily and precisely relate angled abutments to each other and to implant fixtures. The application of this jig is described for a maxillary anterior three-unit implant-supported FPD utilizing two-angled abutments replacing teeth 11,21 , and 23 .

\begin{abstract}
1,20ral and Maxillofacial Prosthodontics Department, Faculty of Dentistry, King Abdulaziz University, Jeddah, Kingdom of Saudi Arabia Corresponding Author: Ahmad Y Imam, Oral and Maxillofacial Prosthodontics Department, Faculty of Dentistry, King Abdulaziz University, Jeddah, Kingdom of Saudi Arabia, Phone: +966504613164, e-mail: amahmowd@kau.edu.sa

How to cite this article: Imam AY, Al-Dabbagh RA. Angled Abutment Transfer Jig: A Technical Report. J Contemp Dent Pract 2020;21(5): 593-596.
\end{abstract}

Source of support: Nil

Conflict of interest: None

\section{Materials and Methods}

The Imam jig was used for the transfer of two-angled abutments from study models to patients' mouth for the fabrication of a maxillary anterior three-unit implant-supported FPD. First, a definitive fixture level impression with polyvinyl siloxane impression material (GC Exafast NDS) and occlusal records were taken. Next, implant replicas were placed in position, and soft resin and die stone were poured to construct the master cast (GC Fujirock). Impression accuracy was verified intraorally with impression posts joined together with red auto-polymerizing acrylic resin (GC Pattern Resin LS). Master maxillary and mandibular casts were mounted, and a diagnostic wax-up was made (Fig. 1), for the construction of provisional FPD, at fixture level. The provisional FPD was then inserted into the patients' mouth.

Afterward, angled abutments were chosen, the selection was guided by the diagnostic wax-up and positions of implant fixtures. The chosen angled abutments ( $17^{\circ}$ pre-angled hexed; Biomet $\left.3 \mathrm{i}\right)$ were then screwed at the desired orientation into the implant replicas, and a screw retained definitive metal ceramic FPD was fabricated. To fabricate the Imam transfer jig, the definitive FPD

() The Author(s). 2020 Open Access This article is distributed under the terms of the Creative Commons Attribution 4.0 International License (https://creativecommons. org/licenses/by-nc/4.0/), which permits unrestricted use, distribution, and non-commercial reproduction in any medium, provided you give appropriate credit to the original author(s) and the source, provide a link to the Creative Commons license, and indicate if changes were made. The Creative Commons Public Domain Dedication waiver (http://creativecommons.org/publicdomain/zero/1.0/) applies to the data made available in this article, unless otherwise stated. 
was removed from the cast and abutment-level pick-up impression coping was seated (Biomet 3i) onto the first angled abutment (on the master cast). Then, an opening was created (hole) with \#330 carbide bur (Henry Schien, Inc.) in the impression-coping part adjacent to the abutment screw as demonstrated in Figure 2. This opening allowed access to abutment screws while the impression coping was still screwed in position (Fig. 3). The process was repeated to the second impression coping. Once, the created slots allowed full access to abutment screws, both copings were secured onto angled abutments. Next, seated impression copings were connected with red acrylic resin (Fig. 4).

Both angled abutments were then unscrewed, accessing screws through created slots, and the whole jig was removed as a one unit. This jig was then transferred to the patient for accurate and quick seating of angled abutments (Fig. 5). Once the jig was in position intraorally, both abutments were screwed into their corresponding implant fixtures, and impression posts were then removed. Finally, abutment screws were torqued following the manufacturer's instructions and then the definitive FPD was screwed into position and adjusted as needed (Fig. 6).

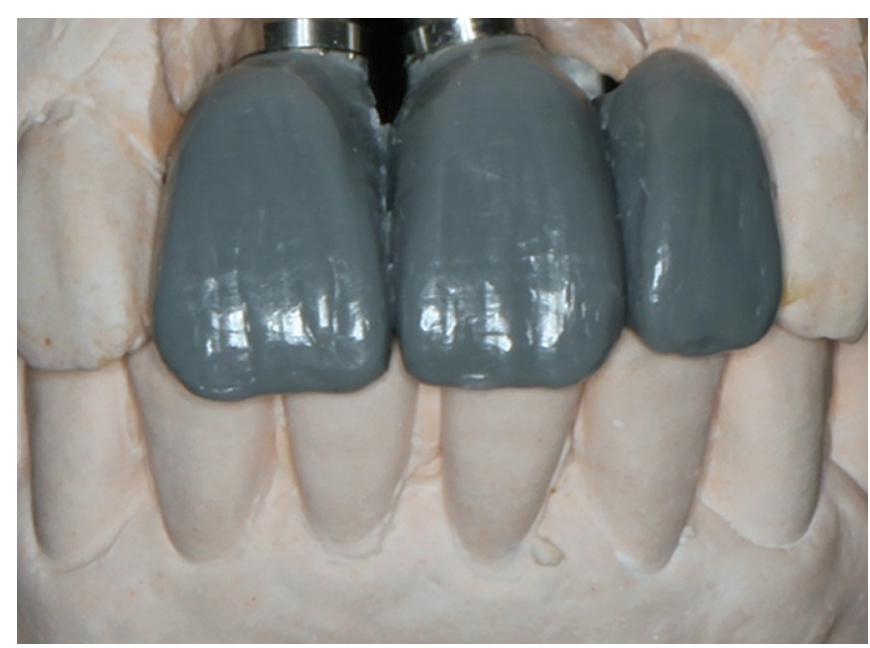

Fig. 1: Diagnostic wax-up used to assist in choosing angled abutments

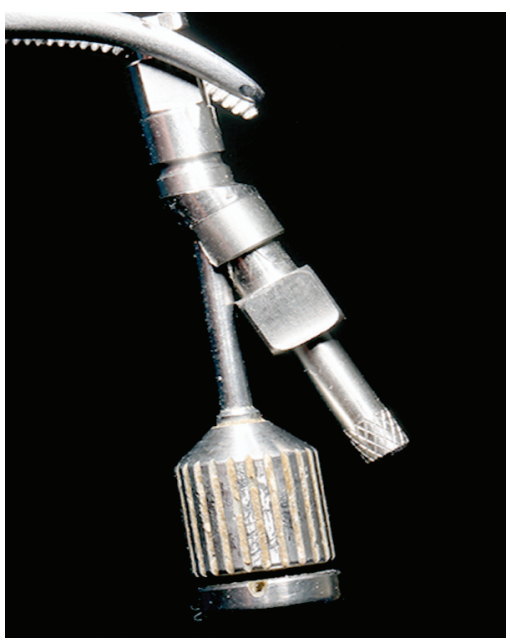

Fig. 3: Created opening, in impression coping, should be large enough to allow access to abutment screw

\section{Discussion}

The use of angled abutments enables dentists to correct implant trajectories as an attempt to increase feasibility to various patients and to reduce cost, time, and complexity of implant-supported prosthesis treatment. ${ }^{1}$ Studies have shown that the use of angled abutments may increase the stress on the prosthesis and surrounding bone, yet there was no significant decrease in survival of implant-supported prosthesis on angled abutment. ${ }^{3,4,10-12}$ However, positioning angled abutments intraorally is timeconsuming because they could be seated at several orientations and thus would usually require a seating jig to ensure correct placement. $^{5-9}$

The presented Imam jig is an angled abutment transfer jig that consists of two impression copings secured on angled abutments which are splinted together with red acrylic resin. Holes were created in both impression copings to allow access to abutment screws, to facilitate screwing-in and -out of implant fixtures. This jig is a one-unit splinted abutment-impression coping-acrylic resin complex. However, most available transfer jigs are fabricated from

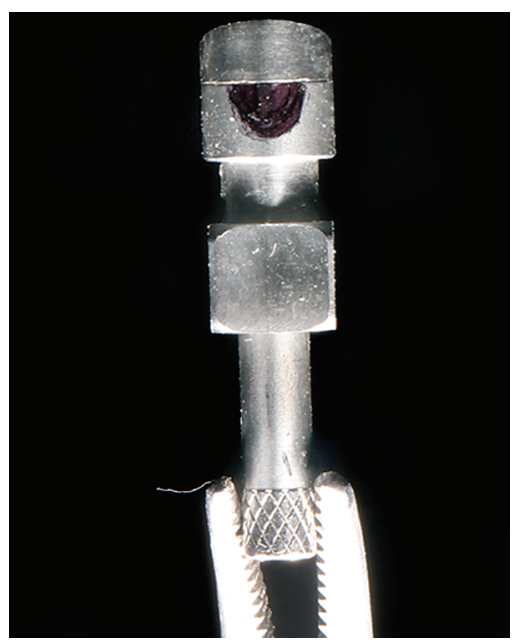

Fig. 2: Pick-up impression coping with the created opening

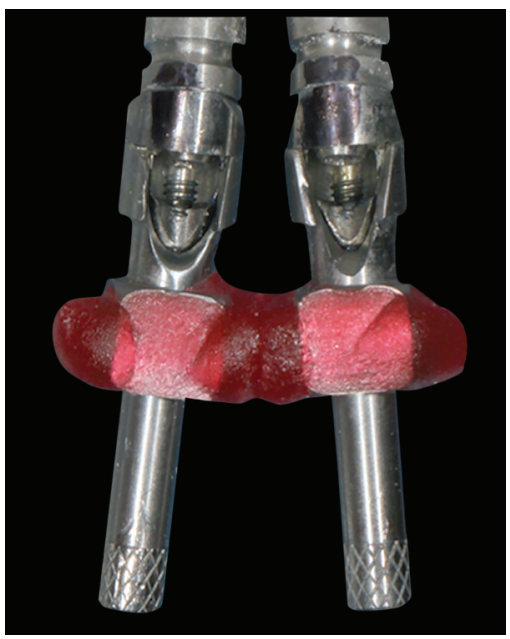

Fig. 4: Securely seated two impression copings that are splinted with red acrylic resin (Imam jig) 
light-polymerizing or auto-polymerizing acrylic resin molded or adapted directly on abutments screwed in position on the master cast. $^{7-9,13}$ These acrylic jigs have slots that guide dentists in the positioning of abutments, but they are not splinted together "abutments-acrylic resin jig." In such jig design, abutments may fall out of place posing a hassle in intraoral reorientation. ${ }^{7-9,13}$

Using a transfer jig that is made exclusively from molded acrylic resin directly on prefabricated, short and conically shaped angled abutments could be a challenging method in providing a seating guide for these abutments. Because of the abutment's small dimensions, they easily fall out of place and the acrylic splint will not be as accurate a positioning guide. Instead, utilizing impression copings and acrylic resin to splint angled abutments in position would facilitate easy and accurate transfer of such abutment's orientation intraorally. ${ }^{5}$ Furthermore, reducing the bulk of used acrylic resin in the Imam jig decreases the resulting polymerization shrinkage and possible inaccuracies in spatial relationships. ${ }^{13,14}$

Additionally, because of the lack of a rigid splint between abutments and the jig, in most available transfer aids, seating abutments into deeply positioned implant fixtures may impinge on soft tissue. This could be problematic and time-consuming to overcome. Yet, because of the proposed jig's rigidity, soft-tissue impingement could be avoided by pushing thick and deep soft tissue away from fixtures and thus simplifying abutment seating in

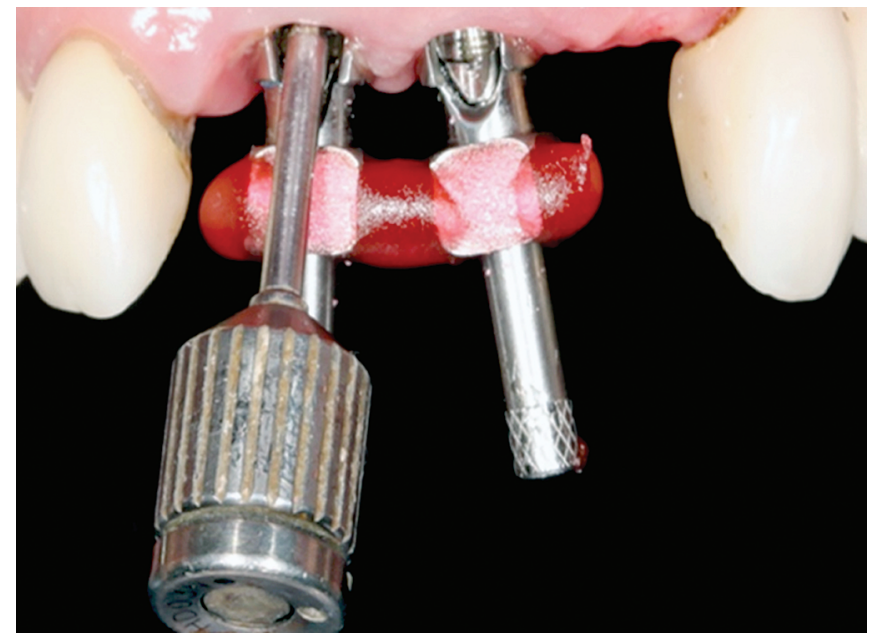

Fig. 5: Transfer of angled abutments intraorally with the Imam jig such clinical cases. Moreover, because of the jig's rigidity, it ensures very precise and easy transfer of abutments into implants with subsequent exact seating of prosthesis.

Wang and Lin fabricated a similar seating jig, to the proposed one, but instead of using impression copings, they used temporary cylinders screwed into abutments. These temporary cylinders were modified by creating holes to allow access to abutment screws. Then, they were splinted together with acrylic resin to create the transfer aid. ${ }^{5}$ This jig is rigid and facilitates easy and quick abutment seating; however, the modified temporary cylinder will not be useable again. Conversely, in the Imam jig, the modified impression copings could be reused for abutment-level impressions or as transfer jigs. This approach reduces waste and is more cost-effective.

In another similar jig that was developed by Mendonça et al., they used impression coping screws, without the coping, tightened on properly positioned angled abutments. The impression coping screws were fastened in position with only two turns. Then, acrylic resin was used to splint these screws, which was retained by the remaining threads of the impression coping screws. To avoid overflow of resin into abutments access holes, wax was used to block these holes temporarily. Once acrylic resin fully polymerized, the jig was then removed as a unit from the cast and used to seat abutments accurately into position intraorally. ${ }^{6}$ In the Imam jig, because impression copings were used, acrylic resin could easily attach to copings at a position that is away from abutments and soft tissue. This method simplifies the laboratory construction of this splint and the clinical transfer of abutment orientation intraorally and thus reducing chairside time.

The Imam jig design is best used for implant-supported FPD utilizing two-angled abutments with external or shallow internal connections. However, a modification could be made when more than two-angled abutments are to be used, for instance, by connecting two or more Imam jigs together (each jig will splint twoangled abutments) with a key and keyway connection in the acrylic resin splint. Thus, overcoming the difficulty encountered in seating multiple-angled abutments with different seating angulations.

Among the limitations of the proposed Imam jig is that it cannot be used with deep internal connection implants, more than 1.5 -mm-deep internal connection. ${ }^{15}$ In such cases, because of the deep internal connection, seating rigidly splinted angled abutments would not be feasible. In such cases, using a nonrigid guiding transfer aid would be a suitable alternative.
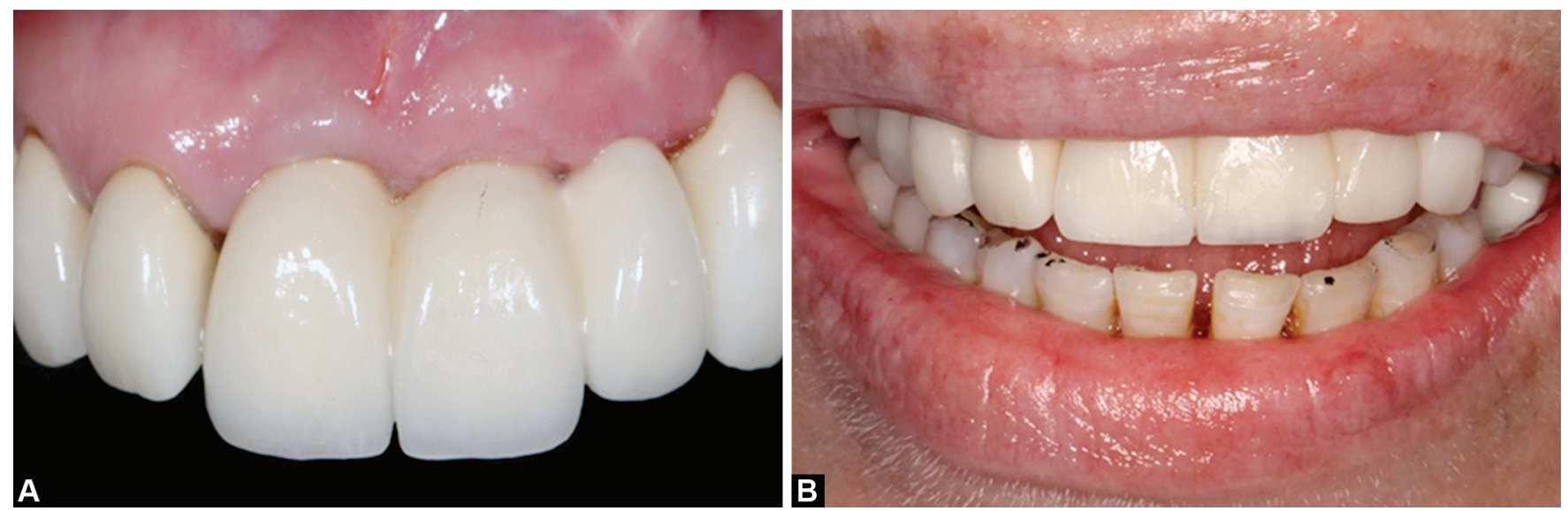

Figs $6 \mathrm{~A}$ and B: Frontal view of the definitive implant-supported FPD screwed in position: (A) intraoral view; (B) extraoral view 


\section{Conclusion}

The Imam jig was used for the restoration of a maxillary anterior implant-supported FPD on two-angled abutments. The introduced jig is rigid and secure to ensure accurate and easy transfer of abutments into implants followed by accurate prosthesis seating.

\section{Clinical Significance}

This transfer jig design allows clinicians to transfer the orientation of angled abutments from cast to patients' mouth with optimal speed and precision.

\section{Author Contribution Statement}

Ahmad Imam contributed to the conception and design of the work, acquisition of the data, interpretation of data for the work, revising it critically, final approval of the version to be published, and agreed to be accountable for all aspects of the work.

Raghad Al-Dabbagh contributed in the design and interpretation of the work, in drafting and the write-up of the manuscript, revising it critically, final approval of the version to be published, and agreed to be accountable for all aspects of the work.

\section{References}

1. Cavallaro J Jr, Greenstein G. Angled implant abutments: a practical application of available knowledge. J Am Dent Assoc 2011;142(2): 150-158. DOI: 10.14219/jada.archive.2011.0057.

2. Celletti R, Pameijer CH, Bracchetti G, et al. Histologic evaluation of osseointegrated implants restored in nonaxial funcional occlusion with preangled abutments. Int J Periodontics Restorative Dent 1995;15(6):562-573.

3. Sethi A, Kaus T, Sochor P, et al. Evolution of the concept of angulated butments in implant dentistry: 14-year clinical data.
Implant Dent 2002;11(1):41-51. DOI: 10.1097/00008505-20020100000013.

4. Goodacre CJ, Kan JY, Rungcharassaeng K. Clinical conplications of osseointegrated implants. J Prosthet Dent 1999;81(5):537-552. DOI: 10.1016/s0022-3913(99)70208-8.

5. Wang TM, Lin LD. A technique to transfer screw-retained angled abutments before inserting a definitive prosthesis. J Prosthet Dent 2006;96(3):222-223. DOI: 10.1016/j.prosdent.2006.06.007.

6. Mendonça G, Fernandes Neto AJ, Neves FD. A customized guide for transferring angled abutments. J Prosthet Dent 2002;87(6):698-699. DOI: $10.1067 / \mathrm{mpr} .2002 .120651$.

7. Al-Abbas $\mathrm{H}, \mathrm{Al}$-Ajmi M, Pipko DJ. A positioning jig to verify the accuracy of implant abutments. J Prosthet Dent 2002;87(1):115-116. DOI: 10.1067/mpr.2002.118920.

8. Jacobson Z, Peterson T, Kim WD. Positioning jig for implant abutments: procedures and clinical applications. J Prosthet Dent 1996;75(4):435-439. DOI: 10.1016/s0022-3913(96)90038-4.

9. Payne J. An alternate light-cured tranfer coping material. J Prosthet Dent 1993;70(4):372-373. DOI: 10.1016/0022-3913(93)90224-c.

10. Clelland NL, Gilat A. The effect of abutment angulation on stress tranfer for an implant. J Prosthodont 1992;1(1):24-28. DOI: 10.1111/j.1532-849x.1992.tb00422.x.

11. Sahin S, Cehreli MC, Yalcin E. The influence of functional forces on the biomechanics of implant-supported prostheses: a review. J Dent 2002;30(7-8):271-282. DOI: 10.1016/s0300-5712(02)00065-9.

12. Lewi $S$, Avera $S$, Engleman $M$, et al. The resotration of impoperly inclinde osseointegrated implants. Int J Oral Mazillofac Implants 1989;4(2):147-152.

13. Zafiropoulos G, Hoffmann O, Deli G. A method of fabrication of implant-supported fixed partial dentures. J Oral Implantol 2001;27(11):271-279.

14. Dumbrigue H, Gurun D, Javid N. Prefabricated acrylic resin bars for splinting implant transfer copings. J Prpsthet Dent 2000;84(1): 108-110. DOI: 10.1067/mpr.2000.107914.

15. Singla S, Kumar L, Rathee M. Know your implant connections. African J Oral Health 2016;6(2):1-7. DOI: 10.4314/ajoh.v6i2.162380. 